\title{
Ranges of movement at the shoulder complex using an electromagnetic movement sensor
}

\author{
G R Johnson, N C M Fyfe, M Heward
}

\begin{abstract}
There are few published data on the ranges of available motion at the shoulder and no clinical technique for the assessment of three dimensional movement. An electromagnetic movement sensor (Isotrak), which makes three dimensional measurements of shoulder movement and measures the ranges of flexion, extension, abduction in the neutral position, abduction preceded by external rotation, and internal rotation achieved by placing the hand as far up the back as possible, was used to study 16 normal subjects.

Intraobserver repeatability was good, and a study of five subjects by two observers showed no significant difference between single measurements made by each. The measured ranges were in broad agreement with published data, though they tended to be smaller. This was attributed to either the bulk of the mounting for the movement sensor or to the immobilisation of the elbow and hence the biceps muscle. Women had greater ranges, except for externally rotated abduction.
\end{abstract}

Mechanical, Materials and Manufacturing

Engineering,

University of Newcastle upon Tyne

G R Johnson

Disablement Services

Centre, Freeman Road,

Newcastle upon Tyne

NE7 7AF

N C M Fyfe

Department of

Physiotherapy, South

Cleveland Hospital,

Middlesbrough

M Heward

Correspondence to:

Dr Fyfe.

Adcepted for publication 2 April 1991
Despite the common occurrence of arthritic and other disabling conditions of the shoulder and the consequent need to evaluate treatment there are few published data on the ranges of movement of the joint complex. Probably the most commonly quoted values are those published by the American Academy of Orthopaedic Surgeons, ${ }^{1}$ which represent averages from earlier published work. Boone and Azen ${ }^{2}$ used traditional goniometers to measure horizontal and forward flexion and extension, abduction, and humeral rotation, and Clarke and colleagues ${ }^{3}$ used hydrogoniometers to measure the ranges of passive abduction and rotation. Allander and colleagues also measured ranges of rotation using a large traditional goniometer. ${ }^{4}$ In the 1950s Salter and Darcus described a specially designed fixture to measure humeral rotation. ${ }^{5}$ Table 1 summarises the published data.

Although the traditional protractor goniometer is convenient in clinical use, the difficulties of initial alignment with the limb and the trunk can lead to appreciable inaccuracies. Boone and colleagues $^{6}$ made a detailed study of the repeatability of goniometer readings and concluded that provided the same observer took all the measurements of the same subject changes of 4 degrees could be detected reliably, though it seems likely that these findings relate to highly trained observers. In their thorough study of the use of hydrogoniometers Clarke et al found standard deviations of $13 \cdot 3,7 \cdot 7$, and $7 \cdot 5$ degrees for measurements of the passive ranges of total humeral rotation, external rotation, and abduction respectively based on eight successive readings taken over four days. ${ }^{3}$

Apart from the problems of repeatability, traditional goniometers are also limited by the fact that they can only make planar measurements of motion which is almost always (in the case of the shoulder) three dimensional and in which small out of plane movements may have a considerable effect on the measured range. Our report describes work using an electromagnetic movement sensor to measure three dimensional shoulder motion; the method of use of this system has been described previously. ${ }^{7}$ This paper reports the measurement of active flexion, extension, abduction, and internal rotation of 16 normal subjects and compares the results of two independent observers who made measurements on five of these subjects.
Table 1 Ranges of motion at the shoulder: published data

\begin{tabular}{|c|c|c|c|}
\hline Authors & Movement & Active/passive & Range (deg) \\
\hline $\begin{array}{l}\text { Allander et al }(1974)^{4} \\
\text { Boone and Azen }(1979)^{2}\end{array}$ & $\begin{array}{l}\text { Humeral rotation } \\
\text { Horizontal flexion } \\
\text { Horizontal extension } \\
\text { Abduction } \\
\text { Forward flexion } \\
\text { Backward extension } \\
\text { Internal rotation } \\
\text { External rotation }\end{array}$ & $\begin{array}{l}\mathbf{P} \\
\mathbf{A} \\
\mathbf{A} \\
\mathbf{A} \\
\mathbf{A} \\
\mathbf{A} \\
\mathbf{A} \\
\mathbf{A}\end{array}$ & $\begin{array}{l}111-125 \\
140 \cdot 7 \\
45 \cdot 4 \\
184 \cdot 0 \\
166 \cdot 7 \\
62 \cdot 3 \\
68 \cdot 8 \\
103 \cdot 7\end{array}$ \\
\hline $\begin{array}{l}\text { Boone et al }(1978)^{6} \\
\text { Clarke et al }(1974)^{3}\end{array}$ & $\begin{array}{l}\text { Humeral rotation } \\
\text { Humeral rotation }\end{array}$ & $\begin{array}{l}\mathbf{A} \\
\mathbf{P} \\
\mathbf{P}\end{array}$ & $\begin{array}{c}96 \cdot 9-104 \cdot 7 \\
158-159 \cdot 7 \\
98 \cdot 9-101 \cdot 8\end{array}$ \\
\hline $\begin{array}{l}\text { Salter and Darcus }(1953)^{5} \\
\text { AAOS* (average) }^{1}\end{array}$ & $\begin{array}{l}\text { Humeral rotation } \\
\text { Horizontal flexion } \\
\text { Abduction } \\
\text { Forward flexion } \\
\text { Backward extension } \\
\text { Internal rotation } \\
\text { External rotation }\end{array}$ & $\begin{array}{l}\text { A } \\
\text { A } \\
\text { A } \\
\text { A } \\
\text { A } \\
\text { A } \\
\text { A }\end{array}$ & $\begin{array}{l}134-141 \\
135 \\
170 \\
158 \\
53 \\
70 \\
90\end{array}$ \\
\hline
\end{tabular}

${ }^{*}$ AAOS $=$ American Academy of Orthopaedic Surgeons.
Methods

The Isotrak system (Polhemus Navigation Systems, USA) for the measurement of shoulder movement operates by attachment of an electromagnetic source to the upper arm using a moulded thermoplastic splint, which encompasses the elbow in order to locate the humerus, and a small sensor attached over the sternum using adhesive tape (fig 1). Four different test manoeuvres were measured as follows: (a) flexion/extension in the saggital plane; (b) abduction in the frontal plane, forearm pointing forward (abduction (N)); (c) abduction in the frontal plane, preceded by external rotation (abduction (ER)); (d) abduction and internal rotation achieved by the subject placing the arm as high up the back as possible. 


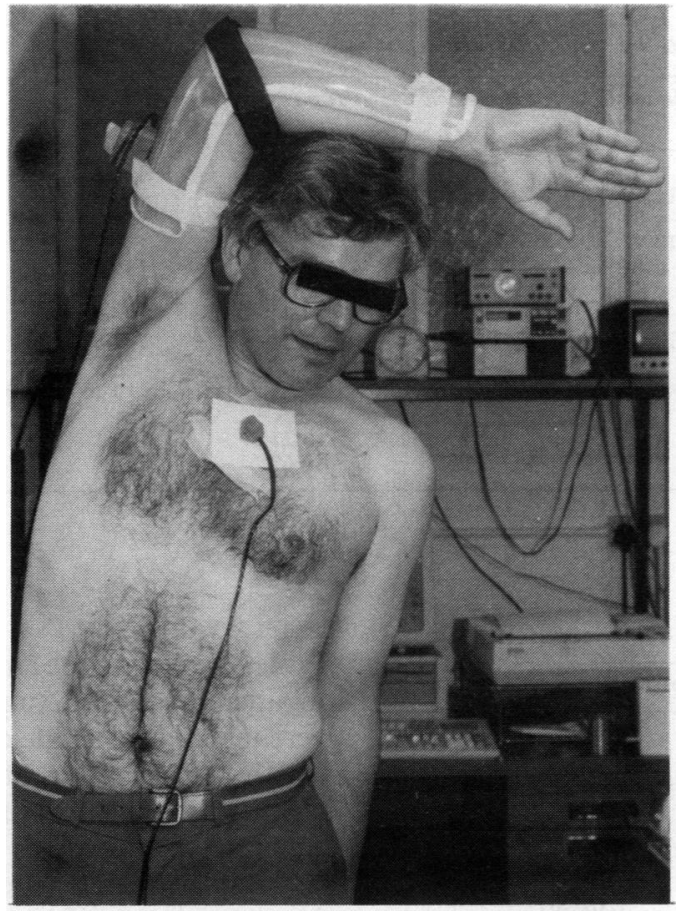

Figure 1 The Isotrak system.

Each test movement was started from the neutral position, which was carefully checked by the observer.

Specialist software has been written both to calculate the angles of movement and the range of motion achieved in each manoeuvre as follows: $(a)$ flexion, extension, range $=$ flexion + extension; (b) abduction ( $N)$; (c) abduction (ER); (d) internal rotation.

Measurements of all four manoeuvres were carried out on 16 test subjects (11 female/five male) by either one or two (NF, MH) of the authors. Measurements on five of the subjects were made up to five consecutive times to study intraobserver variation; all other measurements were made once' only. The observers were unaware of the data at the time of measurement as the calculation of ranges of motion took place after each set of manoeuvres. Table 2 gives
Table 2 Details of 16 test subjects: 11 female, mean age $39 \cdot 2$ (range 21-77); five male, mean age 52 (range 26-69)

\begin{tabular}{|c|c|c|c|}
\hline \multirow[b]{2}{*}{ Measurement } & \multicolumn{3}{|c|}{ Subjects measured by: } \\
\hline & Observer 1 & Observer 2 & Total No \\
\hline $\begin{array}{l}\text { Repeated observations } \\
\text { Single observations }\end{array}$ & $\begin{array}{r}4 \\
15\end{array}$ & $\begin{array}{l}1 \\
6\end{array}$ & $\begin{array}{r}5 \\
16\end{array}$ \\
\hline
\end{tabular}

details of the subjects and measurements. The subjects were all staff or orthopaedic patients with disorders unrelated to the upper limb in the hospital in which the study was carried out; numbers were limited by the availability of volunteers.

\section{Results}

VARIATION IN CONSECUTIVE MEASUREMENTS

Table 3 shows the results of the consecutive tests, together with the analysis of variance. In all cases the $F$ statistic indicated significant differences between the mean measurements of the five test subjects $(p<0.05)$.

\section{INTEROBSERVER VARIATION}

Figure 2 shows graphically the results obtained from single measurements of five subjects by the two observers; table 4 shows the differences

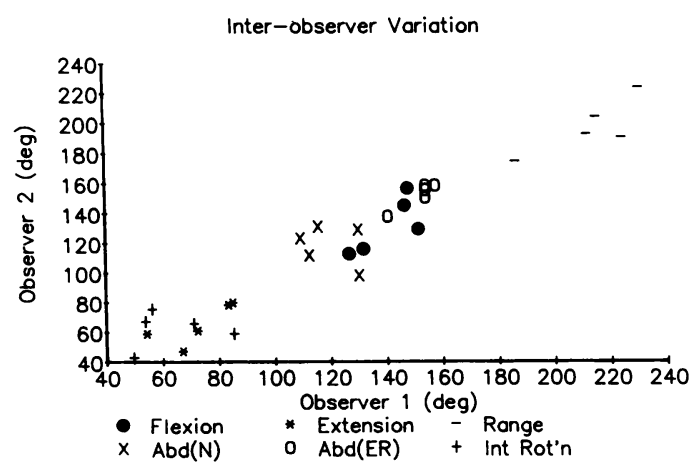

Figure 2 Correlation between measurements of the five subjects by two observers. Abd $(N)=a b d u c t i o n$ in the frontal plane, forearm pointing forward; $A b d(E R)=a b d u c t i o n$ in the frontal plane, preceded by external rotation.

Table 3 Means and standard deviations of repeated measurements of shoulder ranges

\begin{tabular}{|c|c|c|c|c|c|c|}
\hline & \multicolumn{5}{|c|}{ Case No } & \multirow[t]{2}{*}{$F$ statistic } \\
\hline & 1 & 2 & 3 & 4 & 5 & \\
\hline $\begin{array}{l}\text { Flexion } \\
\text { SD } \\
\mathbf{n}\end{array}$ & $\begin{array}{l}56 \cdot 67 \\
(2 \cdot 63) \\
3\end{array}$ & $\begin{array}{l}100 \cdot 83 \\
(11 \cdot 82) \\
3\end{array}$ & $\begin{array}{l}80 \cdot 80 \\
(1 \cdot 76) \\
3\end{array}$ & $\begin{array}{l}58 \cdot 00 \\
(3 \cdot 52) \\
5\end{array}$ & $\begin{array}{l}71 \cdot 23 \\
(11 \cdot 02) \\
3\end{array}$ & $22 \cdot 37$ \\
\hline $\begin{array}{l}\text { Extension } \\
\text { SD } \\
\mathbf{n}\end{array}$ & $\begin{array}{l}139 \cdot 80 \\
(6 \cdot 88) \\
3\end{array}$ & $\begin{array}{l}144 \cdot 20 \\
(4 \cdot 69) \\
3\end{array}$ & $\begin{array}{l}122 \cdot 07 \\
(9 \cdot 56) \\
3\end{array}$ & $\begin{array}{l}114 \cdot 62 \\
(6 \cdot 81) \\
5\end{array}$ & $\begin{array}{l}147 \cdot 50 \\
(9 \cdot 91) \\
3\end{array}$ & 13.45 \\
\hline $\begin{array}{l}\text { Abduction (N) } \\
\mathbf{n}\end{array}$ & $\begin{array}{l}113 \cdot 2 \\
(10 \cdot 80) \\
3\end{array}$ & $\begin{array}{l}126 \cdot 07 \\
(6 \cdot 15) \\
3\end{array}$ & $\begin{array}{l}134 \cdot 20 \\
(1 \cdot 65) \\
3\end{array}$ & $\begin{array}{l}103 \cdot 9 \\
(5 \cdot 03) \\
5\end{array}$ & $\begin{array}{l}127 \cdot 3 \\
(15 \cdot 53) \\
3\end{array}$ & $7 \cdot 65$ \\
\hline $\begin{array}{l}\text { Abduction (ER) } \\
\text { SD } \\
\mathbf{n}\end{array}$ & $\begin{array}{l}149 \cdot 37 \\
(4 \cdot 79) \\
3\end{array}$ & $\begin{array}{l}175 \cdot 55 \\
(0 \cdot 92) \\
2\end{array}$ & $\begin{array}{l}152 \cdot 87 \\
(5 \cdot 72) \\
3\end{array}$ & $\begin{array}{l}121 \cdot 58 \\
(2 \cdot 87) \\
5\end{array}$ & $\begin{array}{l}178 \cdot 10 \\
3\end{array}$ & $141 \cdot 1$ \\
\hline $\begin{array}{l}\text { Internal rotation } \\
\mathbf{S D} \\
\mathbf{n}\end{array}$ & $\begin{array}{l}62.45 \\
(0.35)\end{array}$ & $\begin{array}{l}52 \cdot 00 \\
(1 \cdot 70) \\
2\end{array}$ & $\begin{array}{l}86 \cdot 60 \\
(5 \cdot 23) \\
2\end{array}$ & $\begin{array}{l}39 \cdot 38 \\
5 \\
5\end{array}$ & $\begin{array}{l}74 \cdot 77 \\
3 \\
3\end{array}$ & $37 \cdot 45$ \\
\hline
\end{tabular}


Table 4 Differences (observer 1-observer 2), mean differences, 95 per cent confidence intervals, and mean absolute differences between measurements by two observers

\begin{tabular}{|c|c|c|c|c|c|c|}
\hline Case No & Flexion & Extension & Range & $A b d(N)$ & $A b d(E R)$ & $\begin{array}{l}\text { Internal } \\
\text { rotation }\end{array}$ \\
\hline $\begin{array}{l}6 \\
7 \\
8 \\
9 \\
3\end{array}$ & $\begin{array}{r}5 \cdot 07 \\
11 \cdot 59 \\
-4 \cdot 51 \\
19 \cdot 97 \\
-6 \cdot 14\end{array}$ & $\begin{array}{l}13.82 \\
21.95 \\
15.89 \\
-9 \cdot 23 \\
-0.35\end{array}$ & $\begin{array}{l}18 \cdot 89 \\
33 \cdot 54 \\
11 \cdot 38 \\
10 \cdot 75 \\
-6 \cdot 49\end{array}$ & $\begin{array}{r}-0.93 \\
-0.88 \\
-32.09 \\
15.33 \\
13.81\end{array}$ & $\begin{array}{r}4.39 \\
-2 \cdot 70 \\
0.98 \\
-3.50 \\
1.67\end{array}$ & $\begin{array}{r}-6 \cdot 53 \\
13.36 \\
-26.44 \\
-5 \cdot 57 \\
19 \cdot 27\end{array}$ \\
\hline $\begin{array}{l}\text { Mean } \\
\text { SD }\end{array}$ & $\begin{array}{r}5 \cdot 20 \\
10 \cdot 98\end{array}$ & $\begin{array}{r}8 \cdot 42 \\
12 \cdot 81\end{array}$ & $\begin{array}{l}13 \cdot 61 \\
14 \cdot 51\end{array}$ & $\begin{array}{r}-0.95 \\
19.06\end{array}$ & $\begin{array}{l}0.17 \\
3.26\end{array}$ & $\begin{array}{r}-1 \cdot 18 \\
18 \cdot 14\end{array}$ \\
\hline $95 \%$ confidence intervals & 15.02 to -4.62 & $19 \cdot 88$ to & -3.0426 .59 to 0.63 & $16 \cdot 10$ to & -18.006 .18 to 0.34 & 34.36 to 1.92 \\
\hline $\begin{array}{l}\text { Mean absolute differences } \\
\text { SD }\end{array}$ & $\begin{array}{l}9 \cdot 46 \\
6 \cdot 51\end{array}$ & $\begin{array}{r}12 \cdot 25 \\
8 \cdot 07\end{array}$ & $\begin{array}{l}16 \cdot 21 \\
10 \cdot 67\end{array}$ & $\begin{array}{l}12 \cdot 61 \\
12 \cdot 87\end{array}$ & $\begin{array}{l}2 \cdot 65 \\
1 \cdot 37\end{array}$ & $\begin{array}{r}14 \cdot 23 \\
8 \cdot 80\end{array}$ \\
\hline
\end{tabular}

Table 5 Mean (SD) ranges of motion for the group of 16 normal subjects

\begin{tabular}{|c|c|c|c|c|}
\hline \multirow[t]{2}{*}{ Movement } & \multicolumn{2}{|c|}{ This study } & \multicolumn{2}{|c|}{ Previous workers } \\
\hline & $\begin{array}{l}M \\
(n=5)\end{array}$ & $\begin{array}{l}F \\
(n=11)\end{array}$ & & \\
\hline Flexion & $\begin{array}{l}127 \cdot 6 \\
(18 \cdot 4)\end{array}$ & $\begin{array}{l}140 \cdot 7 \\
(15 \cdot 5)\end{array}$ & $\begin{array}{l}166 \cdot 7 \\
158\end{array}$ & $\begin{array}{l}\text { (Boone and Azen })^{2} \\
(\text { AAOS })^{1}\end{array}$ \\
\hline Extension & $\begin{array}{r}63.9 \\
(13.5)\end{array}$ & $\begin{array}{c}70 \cdot 5 \\
(15 \cdot 9)\end{array}$ & $\begin{array}{l}62 \cdot 3 \\
53\end{array}$ & $\begin{array}{l}\text { (Boone and Azen })^{2} \\
(\text { AAOS })^{1}\end{array}$ \\
\hline Range* & $\begin{array}{l}191 \cdot 5 \\
(24 \cdot 5)\end{array}$ & $\begin{array}{l}211 \cdot 2 \\
(18 \cdot 92)\end{array}$ & $\begin{array}{l}229 \\
211\end{array}$ & $\begin{array}{l}\text { (Boone and Azen })^{2} \\
(\text { AAOS })^{1}\end{array}$ \\
\hline Abduction (N) & $\begin{array}{l}117 \cdot 0 \\
(25 \cdot 2)\end{array}$ & $\begin{array}{l}130 \cdot 3 \\
(11 \cdot 6)\end{array}$ & $100 \cdot 5$ & $(\text { Clarke et } a l)^{3}$ \\
\hline Abduction (ER) & $\begin{array}{l}168 \cdot 5 \\
(50 \cdot 0)\end{array}$ & $\begin{array}{l}160 \cdot 8 \\
(19 \cdot 5)\end{array}$ & $\begin{array}{l}184 \cdot 0 \\
170\end{array}$ & $\begin{array}{l}\text { (Boone and Azen })^{2} \\
(\text { AAOS })^{1}\end{array}$ \\
\hline Internal rotation & $\begin{array}{r}52 \cdot 3 \\
(19 \cdot 6)\end{array}$ & $\begin{array}{l}67 \cdot 1 \\
(16 \cdot 3)\end{array}$ & $\begin{array}{l}68 \cdot 8 \\
70\end{array}$ & $\begin{array}{l}\text { (Boone and Azen) } \\
(\text { AAOS })^{1}\end{array}$ \\
\hline
\end{tabular}

${ }^{*}$ Calculated as flexion+extension.

\section{SAMPLE VARIATION}

Table 5 shows the mean ranges of motion obtained for all 16 subjects. All of these data were taken from single observations by observer 1 with the exception of the data on observer 1 which were, by necessity, made by observer 2 . Figure 3 summarises the data graphically, showing the means (standard deviations) of the six measurements for male and female subjects.

\section{Discussion}

The technique presented here allows, for the first time, comprehensive assessment of active motion at the shoulder complex using a common reference starting position for all measurements. The interobserver and intraobserver studies showed that although one observer can obtain repeatable measurements there can, in some cases, be large interobserver differences. This finding is consistent with the work of Boone and colleagues ${ }^{6}$ and is thought to represent differences of both the definition of starting positions and subject motivation. The $F$ statistics, however, show that the technique was sufficiently reliable to detect differences between the subjects for all measurements. It is also interesting to note that, in general, the interobserver differences are not consistent, that is to say observer 1 does not always achieve higher readings than observer 2 . An exception to this is the measurement of the overall range of flexion/ extension, where the definition of a starting point is irrelevant, for which observer 1 produces consistently higher readings. This supports the suggestion that for the other results it is variation of the initial zero which causes much of the unreliability. The most reliable measurements seem to be those of abduction (ER), though it is not clear why this should be so; the most unreliable are those of internal rotation, which may reflect slightly varying interpretations of the manoeuvre. Overall, these findings support the suggestion of Boone and colleagues ${ }^{6}$ that sequential studies should be carried out by one observer.

Table 5 gives a comparison of the results obtained here and those of other studies. It is interesting to note that, with the exception of extension and abduction ( $\mathbf{N})$, all the ranges reported here are smaller than those from other studies. The relatively close agreement for the overall ranges of flexion/extension once again

Figure 3 Mean ranges (standar. deviation) of shoulder motion of male and female subjects. 
suggests that differences in the initial zero point may be responsible. In addition to variations in the starting position, there may also be differences in the definition of anatomical planes resulting from the method of attachment of the sternum reference marker as well as a slight restriction of movement caused both by the bulk of the attachment and the immobilisation of the elbow. Although the ranges of abduction (ER) agree reasonably well with published data, those of abduction $(\mathrm{N})$ are considerably smaller than many published values (see table 1). This is to be expected as movement in this position is limited by impingement. Measurements of internal rotation are not truly comparable as the published figures were obtained with the shoulder in forward flexion. The finding that women have greater ranges of movement than men is in general agreement with the results of Allander and colleagues. ${ }^{4}$ There also seems to be a trend for ranges to decrease with age, but the number of subjects in this study was too small to allow statistical analysis.

\section{Conclusions}

It has been shown in this paper that comprehensive data on mobility of the shoulder complex may be obtained using Isotrak. Although the repeatability of sequential measurements has been found to be good, there are in some cases large discrepancies between the results from different observers, which can, to a certain extent, be attributed to variations in the starting position but are worthy of further study. These problems. have already led to a modification of the Isotrak software requiring an alignment procedure to be performed before measuring the subject.

The mean measured ranges for the 16 subjects agree reasonably well with other published results and tend to be smaller. It is thought that this may be caused partly by immobilisation of the elbow and, in particular, the biceps muscle.
It is also possible that the bulk of the arm splint impeded movement. After investigation of these problems there is a need to examine the influence of age and sex on ranges of movement and to study differences between dominant and non-dominant shoulders.

All the data presented here are concerned with total movement of the shoulder complex and there has been no attempt to separate scapular and glenohumeral movements. Although direct measurement of scapular movement will not be possible with this system, analysis of the three dimensional rigid body motion of the humerus can be achieved. Techniques to do this are currently under development.

In conclusion, Isotrak has been shown to be a suitable tool for the measurement of shoulder movement. Although its use may be a little too time consuming for routine clinical use, it will be valuable for the study of treatment methods and joint replacement.

The authors are grateful to the patients and staff of Middlesbrough General and Hemlington Hospitals who volunteered as subjects and to Dr Mike Cox, department of engineering mathematics, University of Newcastle upon Tyne, for assistance with the statistical aspects of the paper.

1 American Academy of Orthopaedic Surgeons. Foint motion: method of measuring and recording. Chicago: American Academy of Orthopaedic Surgeons, 1965.

2 Boone D C, Azen S P. Normal range of motion of joints in male subjects. F Bone foint Surg [Am] 1979; 61: 756-9.

3 Clarke G R, Willis L A, Fish W W, Nichols P J R. Assessment of movement at the glenohumeral joint. Orthopedics 1974; 7: 55-71.

4 Allander $\mathrm{O}$, Bjornsson $\mathrm{O} J$, Olafsson $\mathrm{O}$, Sigfusson $\mathrm{N}$, Thorsteinsson J. Normal range of joint movements in Thorsteinssonts in shoulder, hip, wrist and thumb with special reference to side: a comparison between two populations. Int $\mathcal{J}$ Epidemiol 1974, 3: 253-61.

Saiter $N$, Darcus $H$ D. The amplitude of forearm and of humeral rotation. F Anat 1953; 87: 407-18.

6 Boone D C, Azen S P, Lin C, Spence C, Baron C, Lee L. Reliability of goniometry measurements. Phys Ther 1978; 58: $1355-60$.

7 Johnson G R, Anderson J M. Measurement of three dimensional shoulder movement by an electromagnetic sensor. Clinical Biomechanics 1990; 5: 131-6. 